\title{
Electro-fragmentation analysis of dielectric thin films on flexible polymer substrates
}

\author{
Albert Pinyol, Bastian Meylan, Damien Gilliéron, Vinodh Mewani, Yves Leterrier *, Jan-Anders E. Månson \\ Laboratoire de Technologie des Composites et Polymères (LTC), Ecole Polytechnique Fédérale de Lausanne (EPFL), CH 1015 Lausanne, Switzerland
}

\section{A R T I C L E I N F O}

\section{Article history:}

Received 4 September 2008

Received in revised form 24 October 2008

Accepted 27 October 2008

Available online 6 November 2008

\section{Keywords:}

Flexible electronics

Mechanical integrity

Electrical resistance

Amorphous graphite

\begin{abstract}
A B S T R A C T
An electro-fragmentation method was developed as a fast alternative to the time consuming fragmentation test carried out in situ in a microscope, to investigate the failure of dielectric inorganic coatings on polymer substrates. An ultrathin conductive layer was used to probe the onset of tensile failure in the dielectric coating through changes of its electrical resistance. A careful selection of the conductive layer has been carried out to avoid artifacts resulting for instance from a change of the cohesive properties (e.g. internal stress state) of the investigated structures. Au layers were found to be too ductile, contrary to Al-Ti layers that were too brittle, which invalidated the use of both materials to probe the failure of the dielectric coatings. In contrast, for structures on high-temperature polymer substrates, a $10 \mathrm{~nm}$ thick amorphous graphite (a-G) layer was found to accurately reproduce the cracking of the coating. The Young's modulus and coefficient of thermal expansion of the a-G layer are low enough not to impact the internal strain, hence the crack onset strain of the dielectric coating. The a-G layer is also sufficiently brittle, and its cohesive failure and resulting increase of electrical resistance is triggered by the failure of the dielectric coating. The a-G electro-fragmentation method is presently limited to polymers substrates with a glass-transition temperature higher than $100{ }^{\circ} \mathrm{C}$.
\end{abstract}

(C) 2008 Elsevier B.V. All rights reserved.

\section{Introduction}

Mechanical integrity is a key issue in the design, manufacture and operational life of thin film devices arising from various domains in nanotechnology and biomaterials. These include implants coated with biocompatible thin films, nano-engineered textiles with tailored properties and flexible electronic systems -like rollable displays, e-books and solar cells- developed on compliant polymer substrates. In the latter applications, lack of dimensional stability and problems with mechanical failure are mainly due to the considerable hygro-thermo-mechanical contrast between the inorganic, brittle device layers (e.g., $\mathrm{SiN}_{\mathrm{x}}$ and $\mathrm{SiO}_{2}$ passivation layers, transparent conducting electrodes, poly-Si thin film transistors) and the polymer substrates [1]. Numerical modeling of device distortion and damage under various loading scenarios are developed to optimize multilayer design and identify stress concentration areas in the device structure [2]. The accuracy of such simulations is related to the availability of a number of input data including the thermomechanical properties of material constituents. Also, the knowledge of critical failure properties such as the crack onset strain of individual layers is essential for proper calibration of the models.

Mechanical analysis of thin films and of devices on flexible substrates is usually carried out under quasi-static tensile, bending and compressive loadings $[3,4]$. The analysis of damage processes under tensile loading in-situ in an optical [5] or scanning electron microscope [6] is an accurate method to determine the cohesive and adhesive properties of

\footnotetext{
* Corresponding author.

E-mail address: yves.leterrier@epfl.ch (Y. Leterrier).
}

the layers. This approach enabled the detection of a transition between stable and unstable crack growth in case of conducting indium tin oxide (ITO) films [7]. The simultaneous measurement of electrical resistance was useful to identify the critical strain for unstable crack growth, related to overall functional failure of the device. It was also used to analyze the interplay between the defect population and the geometry of patterned ITO layers on critical failure $[8,9]$. A similar approach was used to study the appearance of micro-cracks and related failure mechanisms in thin Cu films on polyimide (PI) substrates [10,11]. For these conductive coatings, an important advantage is that the electrical resistance is very sensitive to the presence of the smallest cracks, which may well be undetectable under the microscope.

In the case of dielectric coatings, an electro-fragmentation method was recently reported [12]. Various conducting materials were used to probe the onset of tensile failure of $\mathrm{SiN}_{\mathrm{x}}$ coatings on polyimide substrates. Amorphous graphite layers were found to be suitable, as these did not affect the internal strain and accurately reproduced the cracking behavior of the nitride coating. The objective of the present work is to extend this electro-fragmentation method using graphite to other dielectric films and polymer substrates. Attention is paid to the onset strain of tensile failure and of electrical resistance increase, and to the influence of process-induced internal strain.

\section{Materials and experimental methods}

\subsection{Dielectric coatings on polymer substrates}

A total of 15 dielectric coating/polymer substrate combinations were considered. Six different polymer substrates were selected 
Table 1

Thermo-elastic $\left(23^{\circ} \mathrm{C}\right)$ and process data

\begin{tabular}{|c|c|c|c|c|}
\hline Material & $\begin{array}{l}\text { Young's modulus } \\
\text { [GPa] }\end{array}$ & $\begin{array}{l}\text { Poisson's } \\
\text { ratio }\end{array}$ & $\begin{array}{l}\text { Coefficient of thermal } \\
\text { expansion }\left[10^{-6} \mathrm{~K}^{-1}\right]\end{array}$ & $\begin{array}{l}\text { Process } \\
\text { temperature }\left[{ }^{\circ} \mathrm{C}\right]\end{array}$ \\
\hline $\mathrm{PI}(10 \mu \mathrm{m})$ & 10 & 0.25 & 30 & - \\
\hline PI $(125 \mu \mathrm{m})$ & 5.4 & 0.25 & 30 & - \\
\hline PET $(12 \mu \mathrm{m})$ & 3.8 & 0.3 & 23 [16] & - \\
\hline PET $(200 \mu \mathrm{m})$ & $\begin{array}{l}4\left(23^{\circ} \mathrm{C}\right) \\
1\left(150^{\circ} \mathrm{C}\right)[39]\end{array}$ & 0.3 & $23[16]$ & - \\
\hline $\operatorname{PEN}(200 \mu \mathrm{m})$ & $\begin{array}{l}5\left(23^{\circ} \mathrm{C}\right) \\
3\left(150{ }^{\circ} \mathrm{C}\right)[39]\end{array}$ & 0.3 & 19 [16] & - \\
\hline ARY $(100 \mu \mathrm{m})$ & 2.9 & 0.38 & 65 & - \\
\hline $\mathrm{SiN}_{\mathrm{x}}$ & 100 & $0.26[40]$ & 10 & $200^{\mathrm{a}}$ or $300^{\mathrm{b}}$ \\
\hline $\mathrm{SiO}_{2}$ & 80 & 0.2 & 2.7 & $\sim 20$ \\
\hline $\mathrm{Al}_{2} \mathrm{O}_{3}$ & 120 [41] & $0.22[41]$ & 3.5 & $\sim 20$ \\
\hline $\mathrm{Au}$ & $54[42]$ & $0.42[43]$ & $14.7[43]$ & $\sim 20$ \\
\hline Al-Ti & 82 [43-45] & $0.34[43-45]$ & $20[43-45]$ & $\sim 20$ \\
\hline$a-G$ & $4.8[44,45]$ & $0.17[44,45]$ & $8[44,45]$ & $\sim 150$ \\
\hline
\end{tabular}

${ }^{\mathrm{a}} \mathrm{SiN}_{\mathrm{x}}$ deposited on $125 \mu \mathrm{m}$ PI.

${ }^{\mathrm{b}} \mathrm{SiN}_{\mathrm{x}}$ deposited on $10 \mu \mathrm{m}$ PI.

giving a broad range of mechanical and physical properties (10 $\mu \mathrm{m}$ thick spin-coated PI and $125 \mu$ m thick PI (Upilex S, UBE), $100 \mu$ m thick high temperature aromatic polyester AryLite (ARY, Ferrania Technologies SpA), $12 \mu \mathrm{m}$ thick polyethylene terephthalate (PET, Mylar 12.0 FA, DuPont), $200 \mu \mathrm{m}$ thick PET (Melinex ST 506/504, DuPont-Teijin Films) and $200 \mu \mathrm{m}$ polyethylene terephthalate (PEN, Teonex Q65FA, DuPont-Teijin Films)). $\mathrm{SiN}_{\mathrm{x}}$ coatings with thickness in the range from 50 to $800 \mathrm{~nm}$ were deposited at $200{ }^{\circ} \mathrm{C}$ and $300{ }^{\circ} \mathrm{C}$ by plasma enhanced chemical vapor deposition (PECVD) on the $125 \mu \mathrm{m}$ and $10 \mu \mathrm{m}$ thick PI films, respectively. Likewise, $\mathrm{SiN}_{\mathrm{x}}$ films were deposited at $300{ }^{\circ} \mathrm{C}$ on ARY substrates. A $48 \mathrm{~nm}$ thick $\mathrm{SiO}_{\mathrm{x}}$ coating was also processed by means of PECVD from an oxygen diluted hexamethyldisiloxane vapor [13] on the $12 \mu \mathrm{m}$ thick PET substrate. A $60 \mathrm{~nm}$ thick $\mathrm{Al}_{2} \mathrm{O}_{3}$ coating was deposited by means of pulsed-DC reactive sputtering from an aluminum target on PET and PEN foils. Investigated structures have been industrially developed for encapsulation of organic light emitting devices and large area lighting devices $\left(\mathrm{Al}_{2} \mathrm{O}_{3} /\right.$ PEN, $\left.\mathrm{Al}_{2} \mathrm{O}_{3} / \mathrm{PET}\right)$, flexible displays $\left(\mathrm{SiN}_{\mathrm{x}} / \mathrm{PI}, \mathrm{SiN}_{\mathrm{x}} /\right.$ Arylite $)[14,15]$ and microwavable food packaging $\left(\mathrm{SiO}_{\mathrm{x}} / \mathrm{PET}\right)$ [16]. The thermo-mechanical properties of individual materials are given in Table 1, and all investigated multilayer films are listed in Table 2.

\subsection{Conducting layers}

Rectangular samples $50 \mathrm{~mm}$ in length and $5 \mathrm{~mm}$ in width were cut from the coated foils and subsequently coated with different conductive layers. Au and Al-Ti layers were sputtered using highpurity targets and conventional argon RF-discharges. The thickness of the $\mathrm{Au}$ and $\mathrm{Al}$-Ti layers was determined using a quartz microbalance and found to be equal to approx. $50 \mathrm{~nm}$ and $25 \mathrm{~nm}$, respectively. Electrical resistivities were found to be of the order of $10^{-5} \Omega \mathrm{m}$ for the Al-Ti layers, whereas in the case of Au layers they were of the order of $10^{-7} \Omega \mathrm{m}$. Amorphous graphite (a-G) layers were produced by means of thermal evaporation from graphite rods, as extensively used in the domain of electron microscopy to yield ultrathin conductive layers of amorphous carbon. The thickness of the $\mathrm{a}-\mathrm{G}$ layers was determined using spectroscopic ellipsometry (GES-5, Sopra) and found equal to $12 \pm$ $1 \mathrm{~nm}$, compared to the $11 \pm 1 \mathrm{~nm}$ estimate obtained from in-situ quartz microbalance during graphite deposition. 11 and $32 \mathrm{~nm}$ thick a-G layers were also deposited on the two types of PI substrates. The electrical resistivity in a-G layers was in the range of $\rho \sim 500-100010^{-6} \Omega \mathrm{m}$, in agreement with data in literature for similar films $[17,18]$ while the tabulated resistivity of bulk graphite is in the $5-5010^{-6} \Omega$ m range [19]. The high electronic conductivity of a-G arises because the disordered carbon atoms are chemically bonded mostly via sp2 type bonding like in crystalline graphite. Hence, our layers are referred as to amorphous graphite, also known as graphite-like carbon. Such increased electrical resistivity originates from loss in carrier mobility in amorphous graphite compared to its crystalline allotrope, and from border effects in the ultrathin (10-20 nm) a-G layers, which reduces the effective cross section for conduction.

\subsection{Thermomechanical properties}

The Young's modulus of the uncoated polymer films and of the inorganic coatings reported in Table 1 was determined using standard tensile tests carried out at $23{ }^{\circ} \mathrm{C}$ [20] and nano-indentation experiments, respectively. The coefficient of thermal expansion (CTE) of the uncoated polymer substrates and of the inorganic coatings was determined using thermo-mechanical analysis, and derived from residual stress analysis [20], respectively. Literature data were used whenever no direct measurements were available.

Table 2

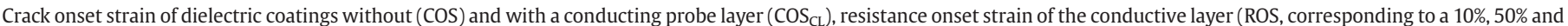
$100 \%$ increase in electrical resistance), and internal strain in the dielectric coating, $\varepsilon_{\mathrm{c}}$. N.M. denotes non-measurable quantities

\begin{tabular}{|c|c|c|c|c|c|c|c|c|c|c|c|}
\hline \multirow[t]{2}{*}{ Substrate } & \multirow{2}{*}{$\begin{array}{l}\text { Substrate } \\
\text { thickness } \\
(\mu \mathrm{m})\end{array}$} & \multirow[t]{2}{*}{ Coating } & \multirow{2}{*}{$\begin{array}{l}\text { Coating } \\
\text { thickness } \\
(\mathrm{nm})\end{array}$} & \multirow{2}{*}{$\begin{array}{l}\text { Conductive } \\
\text { layer }\end{array}$} & \multicolumn{2}{|c|}{ Without conductive layer } & \multicolumn{5}{|c|}{ With conductive layer } \\
\hline & & & & & $\cos (\%)$ & $\varepsilon_{\mathrm{c}}(\%)$ & $\cos _{\mathrm{CL}}(\%)$ & $\operatorname{ROS}(\%) \Delta R / R_{o}=0.1$ & $\operatorname{ROS}(\%) \Delta R / R_{o}=0.5$ & $\operatorname{ROS}(\%) \Delta R / R_{o}=1.0$ & $\varepsilon_{\mathrm{c}}(\%)$ \\
\hline PI & 10 & $\mathrm{SiN}_{\mathrm{x}}$ & 200 & $\mathrm{Au}$ & $0.44 \pm 0.15$ & $-0.22 \pm 0.02$ & $0.47 \pm 0.11$ & 1.15 & 1.22 & 1.25 & - \\
\hline PI & 10 & $\mathrm{SiN}_{\mathrm{x}}$ & 100 & Al-Ti & $0.65 \pm 0.05$ & $-0.34 \pm 0.04$ & $0.35 \pm 0.04$ & $0.31 \pm 0.09$ & $0.46 \pm 0.12$ & $0.51 \pm 0.08$ & $-0.34 \pm 0.06$ \\
\hline PI & 10 & $\mathrm{SiN}_{\mathrm{x}}$ & 50 & $a-G$ & $0.85 \pm 0.17$ & $-0.57 \pm 0.20$ & $0.92 \pm 0.03$ & $0.72 \pm 0.04$ & $0.85 \pm 0.11$ & $0.87 \pm 0.11$ & $-0.26 \pm 0.12$ \\
\hline PI & 10 & $\mathrm{SiN}_{\mathrm{x}}$ & 100 & $a-G$ & $0.65 \pm 0.05$ & $-0.34 \pm 0.10$ & $0.69 \pm 0.01$ & $0.63 \pm 0.03$ & $0.70 \pm 0.02$ & $0.73 \pm 0.03$ & $-0.20 \pm 0.05$ \\
\hline PI & 10 & $\mathrm{SiN}_{\mathrm{x}}$ & 200 & $a-G$ & $0.44 \pm 0.15$ & $-0.22 \pm 0.02$ & $0.42 \pm 0.12$ & $0.44 \pm 0.07$ & $0.49 \pm 0.05$ & $0.51 \pm 0.05$ & $-0.20 \pm 0.02$ \\
\hline PI & 10 & $\mathrm{SiN}_{\mathrm{x}}$ & 400 & $a-G$ & $0.30 \pm 0.10$ & $-0.17 \pm 0.01$ & $0.35 \pm 0.04$ & $0.27 \pm 0.04$ & $0.29 \pm 0.03$ & $0.30 \pm 0.03$ & $-0.20 \pm 0.01$ \\
\hline PI & 125 & $\mathrm{SiN}_{\mathrm{x}}$ & 50 & $a-G$ & $1.32 \pm 0.06$ & N-M. & $1.36 \pm 0.04$ & $1.12 \pm 0.1$ & $1.22 \pm 0.08$ & $1.25 \pm 0.09$ & N-M. \\
\hline PI & 125 & $\mathrm{SiN}_{\mathrm{x}}$ & 100 & $a-G$ & $1.04 \pm 0.10$ & $-0.24 \pm 0.24$ & $1.00 \pm 0.08$ & $0.99 \pm 0.20$ & 1.13 & 1.17 & $-0.30 \pm 0.39$ \\
\hline PI & 125 & $\mathrm{SiN}_{\mathrm{x}}$ & 200 & $a-G$ & $0.83 \pm 0.10$ & $-0.26 \pm 0.02$ & $0.80 \pm 0.05$ & 0.463 & $0.67 \pm 0.07$ & $0.92 \pm 0.09$ & $-0.27 \pm 0.02$ \\
\hline PI & 125 & $\mathrm{SiN}_{\mathrm{x}}$ & 400 & $a-G$ & $0.61 \pm 0.07$ & $-0.22 \pm 0.01$ & $0.58 \pm 0.04$ & 0.538 & 0.576 & 0.597 & $-0.20 \pm 0.01$ \\
\hline PI & 125 & $\mathrm{SiN}_{\mathrm{x}}$ & 800 & $a-G$ & $0.59 \pm 0.06$ & $-0.25 \pm 0.01$ & $0.67 \pm 0.01$ & $0.66 \pm 0.02$ & $0.68 \pm 0.01$ & $0.69 \pm 0.01$ & $-0.21 \pm 0.01$ \\
\hline ARY & 100 & $\mathrm{SiN}_{\mathrm{x}}$ & 400 & $a-G$ & $1.26 \pm 0.12$ & $-1.09 \pm 0.29$ & $1.20 \pm 0.04$ & $0.94 \pm 0.05$ & $1.12 \pm 0.04$ & $1.18 \pm 0.03$ & $-0.94 \pm 0.05$ \\
\hline PEN & 200 & $\mathrm{Al}_{2} \mathrm{O}_{3}$ & 60 & $a-G$ & $0.96 \pm 0.03$ & N-M. & $0.74 \pm 0.05$ & $0.68 \pm 0.04$ & $0.73 \pm 0.05$ & $0.75 \pm 0.06$ & N-M. \\
\hline PET & 200 & $\mathrm{Al}_{2} \mathrm{O}_{3}$ & 60 & $a-G$ & $1.38 \pm 0.05$ & N-M. & $0.82 \pm 0.04$ & $0.86 \pm 0.3$ & $0.89 \pm 0.03$ & $0.91 \pm 0.02$ & N-M. \\
\hline PET & 12 & $\mathrm{SiO}_{\mathrm{x}}$ & 50 & $a-G$ & $1.20 \pm 0.05$ & $-0.29 \pm 0.05$ & $0.92 \pm 0.04$ & $0.76 \pm 0.08$ & $0.88 \pm 0.05$ & $0.91 \pm 0.06$ & $-0.15 \pm 0.02$ \\
\hline PI & 10 & $a-G$ & 11 & - & - & - & $1.03 \pm 0.01$ & 0.975 & 1.09 & 1.14 & N-M. \\
\hline PI & 10 & $a-G$ & 32 & - & - & - & $0.95 \pm 0.01$ & 0.82 & 0.95 & 1.03 & $0.8 \pm 0.3$ \\
\hline PI & 125 & $a-G$ & 11 & - & - & - & $1.36 \pm 0.01$ & & & & \\
\hline PI & 125 & $a-G$ & 32 & - & - & - & $1.21 \pm 0.05$ & & & & \\
\hline
\end{tabular}




\subsection{Internal strain in multilayer structures}

The in-plane internal strains in the dielectric coating with and without the conductive layer, and in the conductive layer were calculated from the radius of curvature of samples, measured at $23 \pm$ $2{ }^{\circ} \mathrm{C}$ and $50 \pm 5 \%$ relative humidity using a digital image analysis tool. This control of relative humidity and of temperature was a key to ensure reproducibility and reliability of the measurements. A thermo-elastic analysis developed for multilayer films was used to calculate the internal strain, following Townsend approach [21]. The internal strain in the coating without the conductive layer was calculated in a first step. It was considered to originate from process-induced effects (intrinsic strain [22]) and from the mismatch in CTE between layers (thermal strain [22]). The thermal strain was calculated from the CTE and process temperature data reported in Table 1 . The intrinsic strain was then added to the thermal strain, so that the calculated radius of curvature matched the measured value. The resulting coating internal strain (thermal strain + intrinsic strain) reported in Table 2 was found to be equivalent to the value calculated directly from Röll bilayer model [23]. The internal strain in the coating after deposition of the conductive layer, and in the

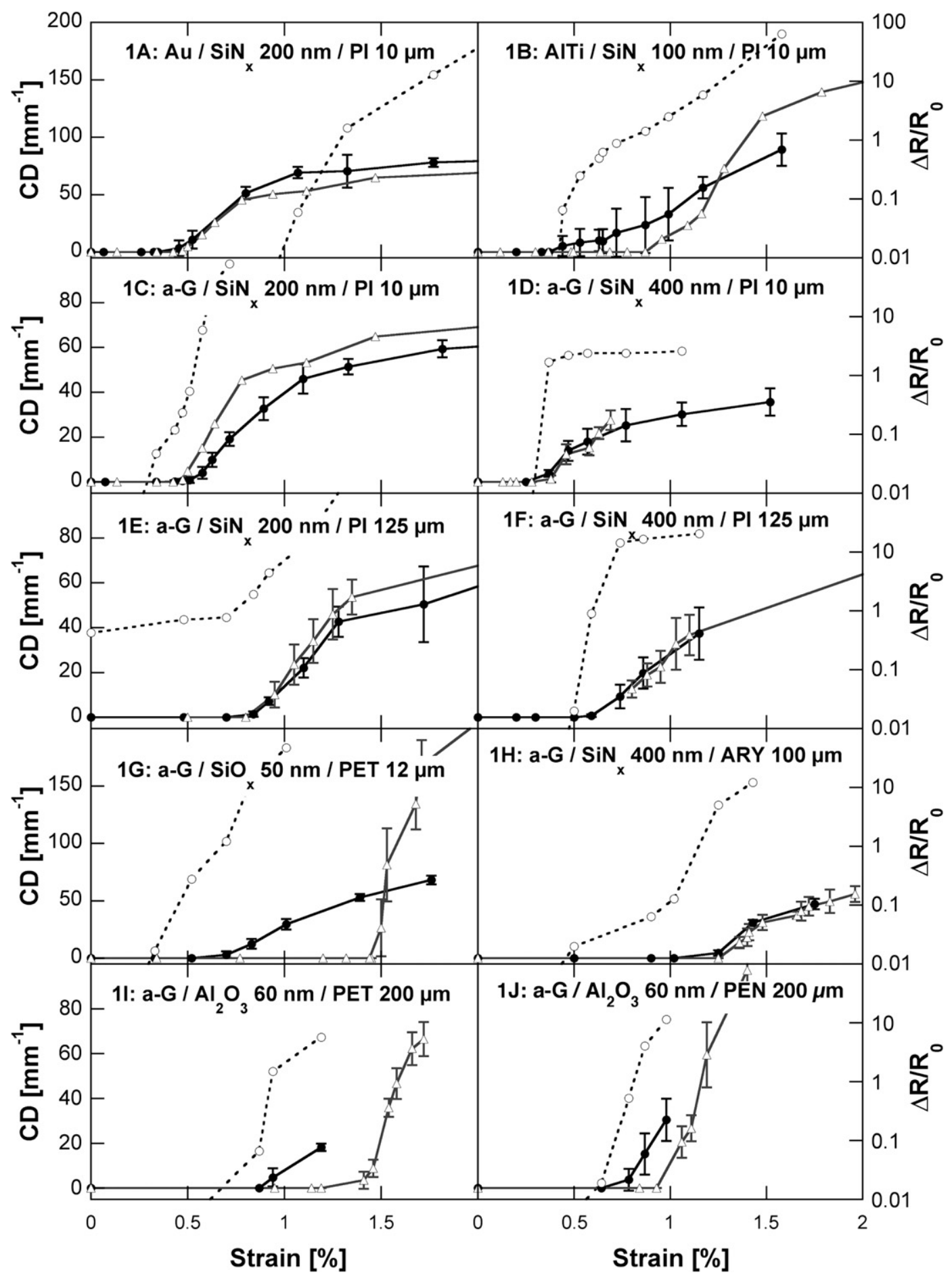

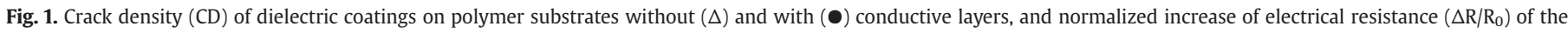

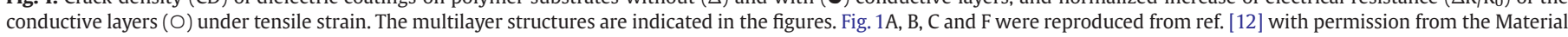
Research Society. 
conductive layer itself were derived assuming that the intrinsic strain in the dielectric coating did not change (the deposition of the conductive layer was carried out well below the critical temperature for the structural change in $\mathrm{SiO}_{\mathrm{x}}, \mathrm{Al}_{2} \mathrm{O}_{3}$ and $\mathrm{SiN}_{\mathrm{x}}$ ) and are also reported in Table 2. As discussed already, some of the polymer substrates shrunk during this deposition step. To account for this phenomenon an effective residual strain in the polymer substrate was added in the calculation to match the measured radius. The internal strain values (Table 2) are estimates since the actual moduli and CTEs are temperature dependent, which was not accounted for. In order to check the accuracy of the present approach, a sensitivity analysis was carried out by changing the properties of the material constituents by a factor of 2 . As detailed in Section 3.2, the resulting change of residual strain in the dielectric coating was in all cases smaller than $2 \times 10^{-4}$, a negligible value. In other words, the present calculation is robust enough to evaluate the influence of the deposition of the conductive layer on the internal strain in the coating.

\subsection{Fragmentation tests}

Fragmentation tests $[24,25]$ were carried out at room temperature under an optical microscope (Olympus BX60). A miniature tensile testing apparatus equipped with special electrical clamps was used. This enabled simultaneous measurement of electrical resistance $R$ and of density of tensile cracks (CD), following a 'stress and stop' approach detailed elsewhere [7]. Video-extensometry was used for accurate strain measurement. The electrical resistance was measured with a multimeter (Hewlett-Packard 3468A and Agilent 34410A). The crack onset strain of the dielectric coating without (COS) and with the conductive layer $\left(\mathrm{COS}_{\mathrm{CL}}\right)$ was determined optically, and compared to the resistance onset strain (ROS) of the conductive layer. Three different values of ROS were defined, as the strain corresponding to a $10 \%, 50 \%$ and $100 \%$ increase in electrical resistance. For each multilayer structure a minimum of three samples were tested.

\section{Results and discussion}

\subsection{Influence of conductive layers on fragmentation of dielectric coatings}

Fig. 1 regroups the results of electro-fragmentation tests for several conductive layer/dielectric coating/polymer stacks [12]. Each individual figure compares the crack density of the dielectric coating with and without the conductive probe layer, and also shows the normalized increase of electrical resistance $\Delta R / R_{0}$ of the conductive layer, where $\Delta R=R-R_{0}$ and $R_{0}$ is the electrical resistance of the unstrained layer. The critical strain values (ROS, COS and $\mathrm{COS}_{\mathrm{CL}}$ ) of investigated multilayer films are reported in Table 2. It is apparent from these values that the resistance onset strain closest to the $C O S$ is given by a resistance increase of $50 \%$. In consequence, we take this result as the definition of the ROS.

In the case of the Au probe layer (Fig. $1 \mathrm{~A}$ ), one finds $\mathrm{COS}_{\mathrm{CL}}=\mathrm{COS}$, a confirmation of the fact that the Au layer did not change the residual strain state of the nitride. This was already noticed in a previous study and was associated with the discontinuous, island-like morphology of very thin Au layers on metal-oxide surfaces [25]. However, the resistance onset strain (Fig. 1A) did not coincide with the crack onset strain of the bare coating (ROS > COS) due to the ductility of gold, which eventually invalidated the use of Au for the electro-fragmentation method. Conversely, in the case of the Al-Ti probe layer (Fig. 1B), it is evident that $\operatorname{COS}_{\mathrm{CL}}<\operatorname{COS}$. This is clearly observed in Fig. 2A-B, which compares the fragmented morphology of the nitride coating on $\mathrm{PI}$ under the same $0.6 \%$ strain, with and without the conductive Al-Ti layer. The nitride coating without the Al-Ti layer was intact, whereas an array of cracks was detected when the Al-Ti layer was present. The same observations were made when a $10 \mu \mathrm{m}$ thick PI was used as substrate. These results invalidated the use of Al-Ti for the electrofragmentation method, in spite of the fact that $\mathrm{ROS}=\mathrm{COS}_{\mathrm{CL}}$. The
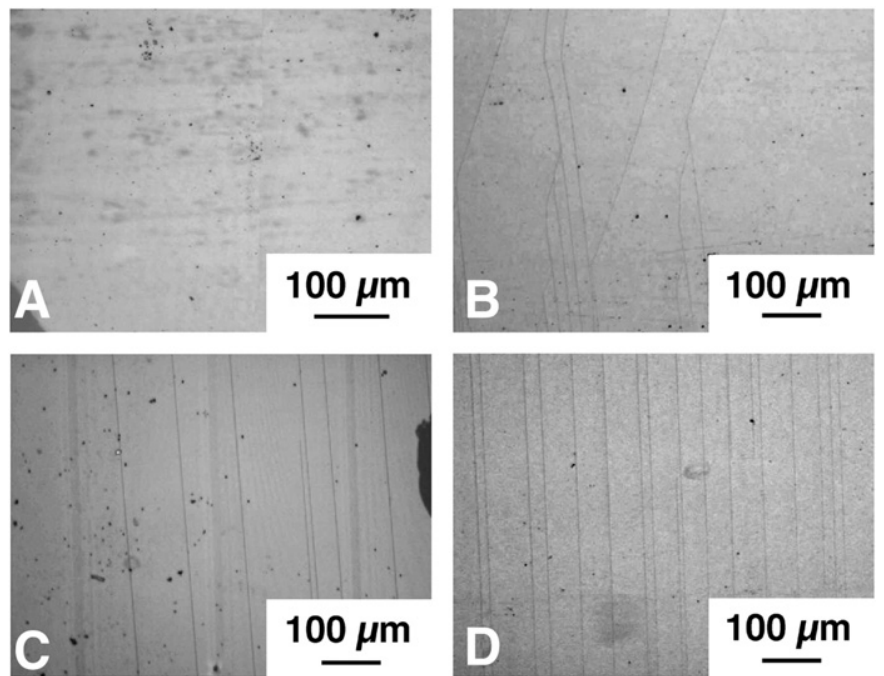

Fig. 2. Fragmentation morphology of a $100 \mathrm{~nm}$ thick $\mathrm{SiN}_{\mathrm{x}}$ coating on a $10 \mu \mathrm{m}$ thick PI substrate under ca. $0.6 \%$ strain, without (A) and with (B) a $25 \mathrm{~nm}$ thick conductive Al-Ti layer. Fragmentation morphology of a $400 \mathrm{~nm}$ thick $\mathrm{SiN}_{\mathrm{x}}$ coating on a $10 \mu \mathrm{m}$ thick PI substrate under ca. $0.5 \%$ strain, without (C) and with (D) a $11 \mathrm{~nm}$ thick conductive a-G layer. The loading direction was parallel to the scale bar.

observed premature failure could be related to process-induced residual stresses introduced in the structure during Al-Ti sputter deposition. It could also result from earlier cracking initiation in the brittle, ultrathin $(\sim 5 \mathrm{~nm})$ superficial native oxide [26] of the Al-Ti layer as was observed in silicon structures $[27,28]$. The exact origin of these cracks could not be resolved under the optical microscope and most likely once initiated the cracks propagated to the adjacent layer due to interfacial stress concentration at crack location [29].

Fragmentation data in the case where amorphous graphite was the conductive layer are shown in Fig. 1C-J. For all $\mathrm{SiN}_{\mathrm{x}} / \mathrm{PI}$ films (Fig. 1C-F), both the crack and resistance onset strains matched that of the uncoated reference $\left(\mathrm{ROS}=\mathrm{COS}_{\mathrm{CL}}=\mathrm{COS}\right)$. Coincidence with the resistance onset was not always clear due to lack of data and to the limited range for resistance measurement above the $30 \mathrm{M} \Omega$. These problems were solved later using extended-range electric test equipment (up to $10 \mathrm{G} \Omega$ ) and shall be improved by using continuous rather than 'stress and stop' measurements. The fragmentation morphology of the $400 \mathrm{~nm}$ thick nitride with and without the a-G layer is shown in Fig. 2C-D. It is evident that cracking has already set off in both cases appearing at a comparable strain. For the $200 \mathrm{~nm}$ thick $\mathrm{SiN}_{\mathrm{x}}$ coating on the thin PI substrate (Fig. 1C) and the $400 \mathrm{~nm}$ thick $\mathrm{SiN}_{\mathrm{x}}$ coating on the ARY substrate (Fig. $1 \mathrm{H}$ ), one may have the feeling that $\mathrm{ROS}<\mathrm{COS}_{\mathrm{CL}}$ but a careful analysis confirmed that the increase of electrical resistance did indeed coincide within experimental scatter with the early stages of tensile failure of the coatings. The definition of the ROS (50\% increase of electrical resistance) is in fact associated with the onset of unstable crack propagation, from which a crack density can be determined.

In the case of $\mathrm{a}-\mathrm{G} / \mathrm{SiO}_{\mathrm{x}} / \mathrm{PET}$ (Fig. $1 \mathrm{G}$ ) and $\mathrm{a}-\mathrm{G} / \mathrm{Al}_{2} \mathrm{O}_{3} / \mathrm{PET}$ (Fig. $1 \mathrm{I}$ ) films one observes that ROS $=\mathrm{COS}_{\mathrm{CL}}<\mathrm{COS}$, similarly to the $\mathrm{Al}-\mathrm{Ti} / \mathrm{SiN}_{\mathrm{x}} / \mathrm{PI}$ case. Again, this may result from a change of residual stress of the dielectric coating upon deposition of the conductive layer, or from early failure of the latter, and will be examined in the following section. The same result was also found in and the case of the $\mathrm{a}-\mathrm{G} / \mathrm{Al}_{2} \mathrm{O}_{3} / \mathrm{PEN}$ film (Fig. 1J), although the difference between ROS and COS was not as large compared to the two previous cases with the PET substrate.

The condition $\operatorname{COS}_{\mathrm{CL}}=\mathrm{COS}$ was verified when a-G layer was used with the PI and ARY substrates, but not with the PET and PEN substrates. These findings imply that the deposition of graphite did not change the residual strain in the nitride, except when the latter two, low temperature polymer substrates were used. This is further examined as follows. 


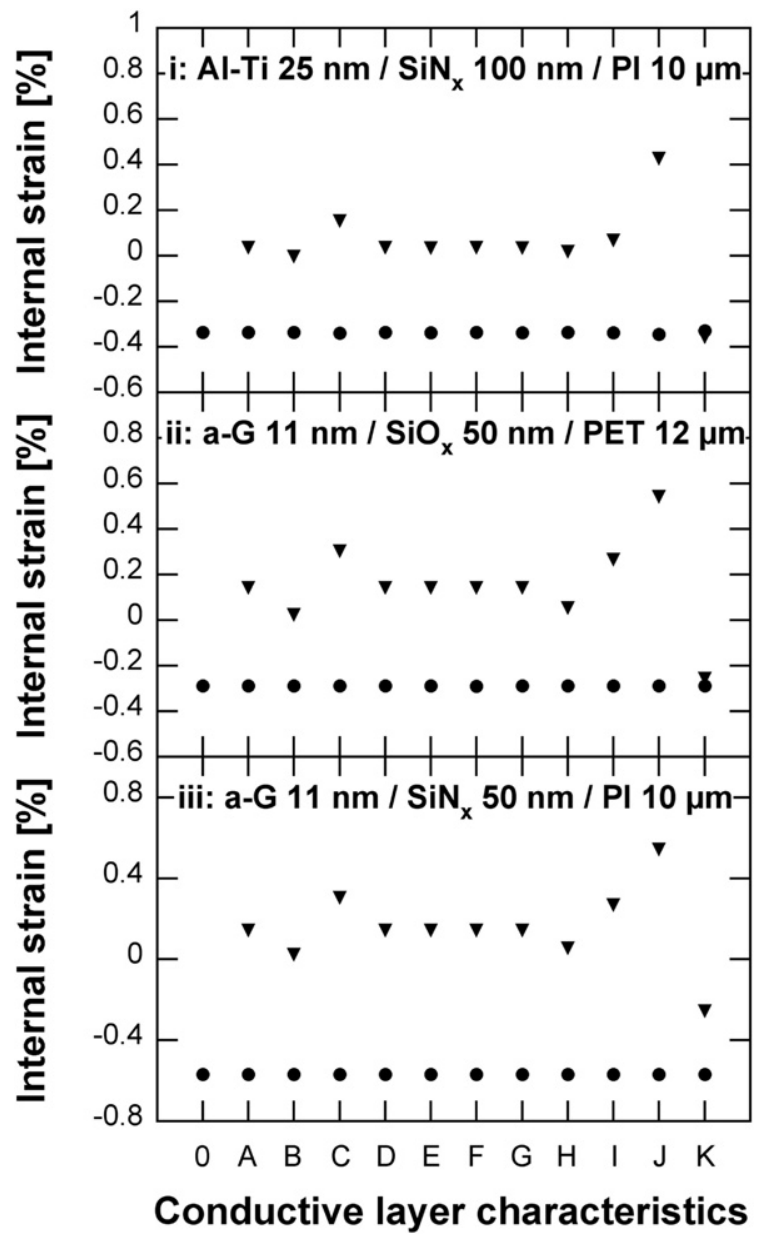

Fig. 3. Internal strain in dielectric coating (circles) and in conductive layer (triangles): (i) AlTi 25 nm/SiN 100 nm/PI $10 \mu \mathrm{m}$; (ii) a-G 11 nm/SiO 50 nm/PET $12 \mu \mathrm{m}$; (iii) a-G 11 nm/SiN $50 \mathrm{~nm} / \mathrm{PI} 10 \mu \mathrm{m}$. Position 0 corresponds to the dielectric coating without conductive layer Positions A-K correspond to specific values of Young's modulus, CTE, layer thickness, deposition temperature and intrinsic strain of the conductive layer (see text for details).

\subsection{Internal strain analysis}

The first criterion to implement electro-fragmentation is that the internal strain state of the dielectric coating does not change upon deposition of the conductive probe layer. This is a priori unavoidable, given the different thermo-elastic properties of the materials that will result in build-up of thermal strains. It may also be influenced by structural changes induced by annealing effects during deposition, such as physical aging of the polymer substrate, resulting in the contraction and the build-up of compressive strains in the coating.

The internal strain in the dielectric coatings prior to deposition of the conductive layer reported in Table 2 was compressive in all investigated cases. This result confirms previous analyses of nitride coatings on PI substrates, in which compressive thermal and intrinsic strains were found to be higher than tensile hygroscopic strains [20]. The internal strain after deposition was also found to be compressive and very close to the reference value in case of PI and ARY substrates, the difference being lower than $0.1 \%$ in all cases. Such a small difference is well within the experimental accuracy of the fragmentation test. This result confirms the validity of the electro-fragmentation method for these materials. In contrast, in the case of the PET and PEN substrates the deposition of the conducting layer was found to decrease the coating COS. This was consistent with the measured decrease of the compressive strain in case of the PET substrate, although the reason for such behavior is unclear. One could think of thermally induced dimensional changes in the polymer substrates during graphite evaporation. Such phenomena may be overcome by minimizing the heating load during processing, either by decreasing the deposition rate or by increasing the sample-tosource distance.

The Young's modulus and CTE of the conducting layers were taken from literature data, which may differ from the actual properties of the layers used in the present work. A sensitivity analysis was performed by increasing and decreasing the deposition temperature $T_{p}$, Young's modulus $E_{C L}, C_{C L}$ and intrinsic strain $\varepsilon_{C L}^{(i)}$ of the graphite and the Al-Ti layers by a factor of 2 while keeping the other properties constant and equal to the values shown in Table 1 . This analysis was carried out for Al-Ti/100 nm SiN $/ 10 \mu \mathrm{m}$ PI, a-G/50 nm SiN $/ 10 \mu \mathrm{m}$ PI and $\mathrm{a}-\mathrm{G} / 50 \mathrm{~nm} \mathrm{SiO}_{\mathrm{x}} / 12 \mu \mathrm{m}$ PET and the results are displayed in Fig. 3. Position 0 corresponds to the internal strain in the coating without the conductive layer. Position A corresponds to the data in Table 1. Positions B and C correspond to deposition temperature $T_{d} / 2$ and $2 T_{d}$, respectively. Positions $\mathrm{D}$ and $\mathrm{E}$ correspond to conductive layer thicknesses $d_{C L} / 2$ and $2 d_{C L}$. Positions $\mathrm{F}$ and $\mathrm{G}$ correspond to elastic modulus $E_{C L} / 2$ and $2 E_{C L}$. Positions $\mathrm{H}$ and I correspond to coefficient of thermal expansion coefficient $C T E_{C L} / 2$ and $2 C T E_{C L}$. Positions $\mathrm{J}$ and $\mathrm{K}$ correspond to intrinsic strain in the conductive layer $\varepsilon^{(i)}{ }_{C L}=+0.4 \%$ and $-0.4 \%$.

The results of these analyses are detailed in Fig. 3. It is evident that the coating internal strain is scarcely changed in all cases, the change being less than $0.02 \%$, regardless of the different properties of the added conductive layer. In contrast, the internal strain in the conductive layer is directly impacted by changing its properties as expected. The negligible change in coating strain with the Al-Ti layer implies that the shift in crack onset strain should be attributed to an earlier failure of the Al-Ti layer, which triggered the cracking of the underlying dielectric coating. It also confirms that the shift in crack onset strain in case of the PET and PEN substrates should be attributed to substrate annealing effects during a-G deposition, rather than from a redistribution of stress in the multilayer structure.

\subsection{Cohesive and structural properties of the graphite layer}

The second criterion for the applicability of the electro-fragmentation method is that the failure of the conductive layer is triggered by the failure of the dielectric coating, and not the opposite. This condition was validated using the electrical measurement (COS$\mathrm{CL}_{\mathrm{C}}=\mathrm{ROS}$ ), and was confirmed by the following analysis. Fig. 4 shows the fragmentation data for $11 \mathrm{~nm}$ and $32 \mathrm{~nm}$ a-G layers deposited on $10 \mu \mathrm{m}$ and $125 \mu \mathrm{m}$ thick PI foils (i.e., without dielectric coating). The

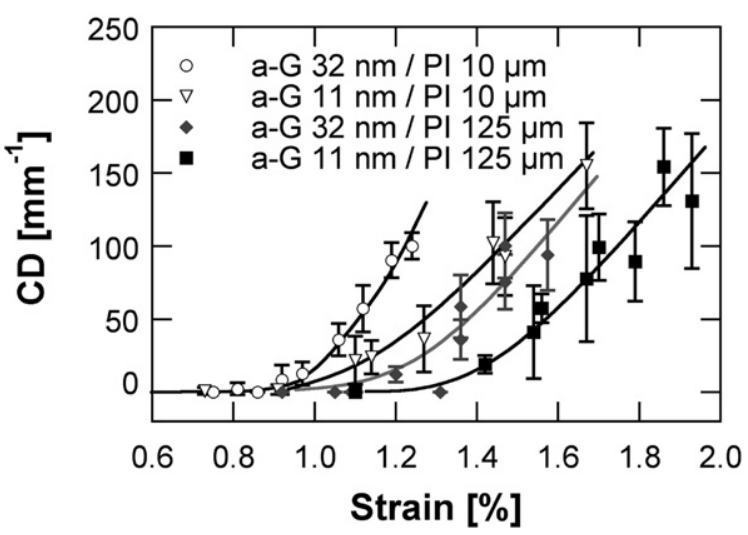

Fig. 4. Crack density vs strain for $11 \mathrm{~nm}$ and $32 \mathrm{~nm}$ thick amorphous graphite layers on $10 \mu \mathrm{m}$ and $125 \mu \mathrm{m}$ thick PI substrates. The lines are guides for the eye. 
COS of the graphite layer was found to be in the range of $0.9-1.4 \%$. The residual strain in the $\sim 11 \mathrm{~nm}$ thick a-G layers could not be measured as such ultrathin layers caused a negligible change in the curvature of the substrate. In the case of $32 \mathrm{~nm}$ thick a-G layers, the residual strain was found to be tensile, and in the range of $0.5-1 \%$, which was attributed to the expansion of the polymer substrate following a-G vacuum evaporation and exposure to air. In consequence, the intrinsic strain to failure of the ultrathin graphite (i.e., the COS in absence of residual stresses) was estimated to be in the range 1.4$2.4 \%$.

When the graphite layer was deposited on the dielectric coating, its residual strain was compressive and estimated to be in the 0.05$0.4 \%$ range. If the coating did not crack, the failure strain of the graphite would be equal to its intrinsic COS, corrected for this residual compressive strain, which would be in the range 1.45$2.8 \%$. The cracking of the dielectric coatings occurred in most cases well below $1.2 \%$ and, in consequence, initiated the failure of the graphite layer, due to local stress concentrations at the graphite/ dielectric interface at the location of cracks in the dielectric coating [29].

These unique properties of the a-G layer result from the specific microstructure produced during evaporation, which was investigated in the case of the $32 \mathrm{~nm}$ thick layer on the $125 \mu \mathrm{m}$ thick Upilex-S substrate using X-ray diffraction (XRD) analysis. An uncoated substrate was also studied as a reference. The XRD patterns (Fig. 5) exhibit crystalline features compatible with Upilex-S [30], and with graphite nanocrystallites that spontaneously incorporate in the amorphous graphite layers during thermal evaporations. Upilex-S is a crystalline polyimide with characteristic peaks corresponding to the (110) doublet, to the (200) and to the (210) families of planes (Fig. 5A). For the a-G coated sample, Fig. 5B, an additional peak is evident around $14.4^{\circ}$, corresponding to a spacing of $6.10 \AA$, slightly away from the graphite characteristic spacing $c=6.71 \AA$. This peak is attributed to the (001) reflection of graphite, which should normally be absent because of systematic extinction conditions. Its presence indicates irregular stacking in the graphite nanocrystallites, which inhibits the perfect extinction of the (001) reflection [31]. In consequence, the peak is significantly broadened, or very small nanocrystallites of a few nanometers in diameter [32]. Adjusting a Lorentzian peak yields a width of $2.1^{\circ}$, corresponding to a dispersion of $\Delta c= \pm 0.5 \AA$. In parallel, Mizes and Foster [33] reported electronic superstructures in graphite with a characteristic periodicity of $4.4 \AA$. The abnormal intensity of the peak at $19.4^{\circ}$, corresponding to a spacing $d=4.6 \AA$, cannot be attributed totally to the Upilex-S component of the XRD signal, and remains unexplained.

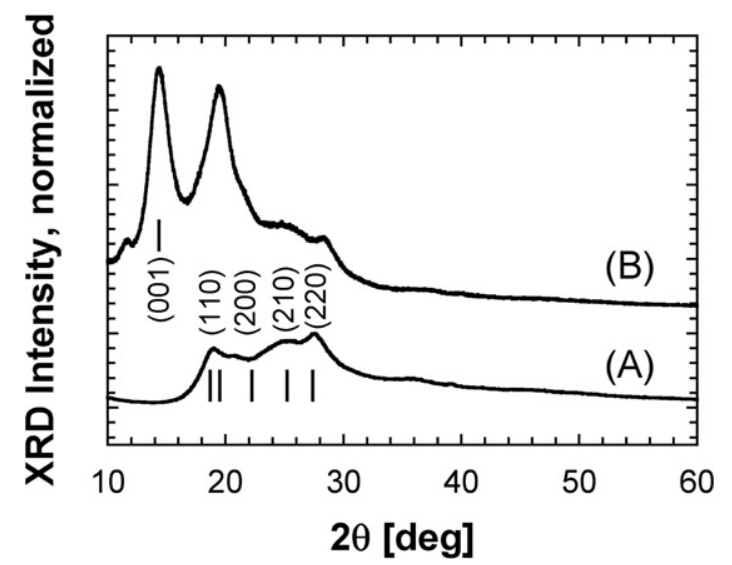

Fig. 5. Normalized XRD patterns of uncoated Upilex-S (A), and a-G layers on Upilex-S substrate (B).

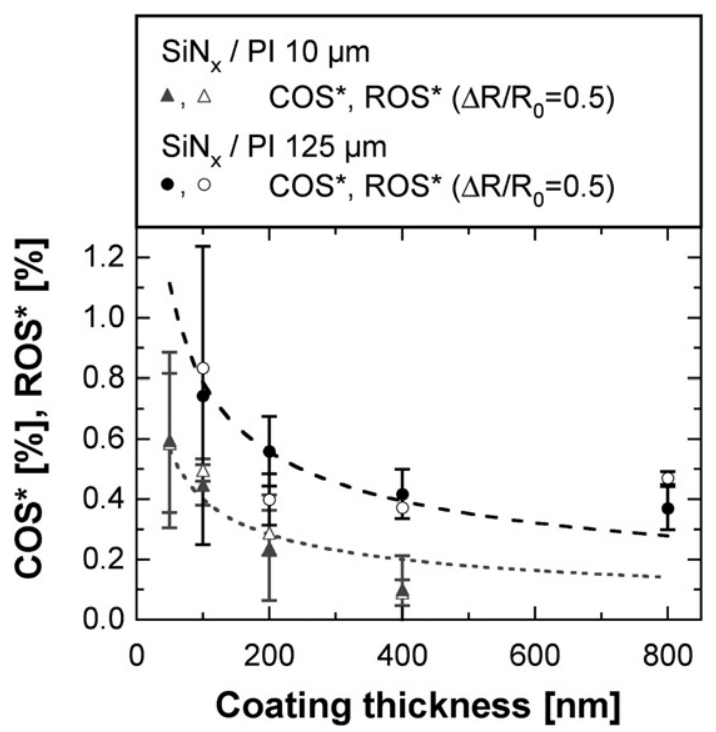

Fig. 6. Intrinsic resistance onset strain $\left(R O S^{*}=R O S+\varepsilon_{c}\right.$, open symbols $)$ and intrinsic crack onset strain $\left(\operatorname{COS}^{*}=\operatorname{COS}+\varepsilon_{c}\right.$, filled symbols) of nitride coatings on $10 \mu \mathrm{m}$ and $125 \mu \mathrm{m}$ thick PI substrates vs coating thickness. The dotted lines represent the fracture mechanics scaling of the ROS* data using adjustable toughness $G_{c}$ of the dielectric coating (see text for details).

\subsection{Application of the electro-fragmentation method to fracture mechanics analysis}

Fracture mechanics analysis predicts the following scaling between the intrinsic crack onset strain, $\operatorname{COS}^{*}$, and the thickness of the coating [34,35]:

$\cos ^{*}=\left(\frac{2 G_{c}\left(1-v_{c}^{2}\right)}{\pi h_{c} E_{c} g(\alpha ; \beta)}\right)^{1 / 2}$

where $G_{c}, \nu_{c}, h_{c}$ and $E_{c}$ represent the fracture toughness, Poisson's ratio, thickness and Young's modulus of the coating and $g(\alpha ; \beta)$ is an elastic contrast function of the Dundurs parameters $\alpha$ and $\beta$ [36]. The intrinsic crack onset strain is equal to the actual crack onset strain corrected for the internal strain $\varepsilon_{c}$ : $\operatorname{COS}^{*}=\operatorname{COS}+\varepsilon_{c}$. The condition $R O S=C O S$ is met when the conductive layer does not change the internal strain in the coating. In this case one can replace the intrinsic COS $^{*}$ in Eq. (1) by $R O S^{*}=R O S+\varepsilon_{c}$. Fig. 6 shows an example of the application of the method, where Eq. (1) is fitted to experimental data with adjustable coating toughness. The function $g(\alpha ; \beta)$ tabulated in [35] is equal to 4.0 for $\operatorname{SiN}_{\mathrm{x}} / 10 \mu \mathrm{m}$ PI, and to 5.7 for $\operatorname{SiN}_{\mathrm{x}} / 125 \mu \mathrm{m}$ PI. The corresponding coating toughnesses were found to be equal to $1.1 \pm 0.2$ and $6.0 \pm 0.7 \mathrm{~J} \mathrm{~m}^{-2}$. The latter result is very close to the value of $6.9 \pm$ $0.7 \mathrm{~J} \mathrm{~m}^{-2}$ found for similar materials in a recent study [37]. This directly translates into a higher resistance to fracture for the $\mathrm{SiN}_{\mathrm{x}}$ deposited at $200{ }^{\circ} \mathrm{C}(125 \mu \mathrm{m} \mathrm{PI})$ compared to that of $\mathrm{SiN}_{\mathrm{x}}$ deposited at $300{ }^{\circ} \mathrm{C}(10 \mu \mathrm{m} \mathrm{PI})$.

The present electro-fragmentation method should be well suited to study the damage evolution in thin film structures under long-term fatigue loading, since optical detection of cracks during experiments that may last several days or weeks would be rather impracticable. Such a method is already established for conductive thin films [38]. Recent studies of the onset of tensile damage in brittle coatings on polymers revealed the existence of very long stable cracks and a progressive transition towards unstable failure (see chapter 6 in [1]). Ongoing research confirms that such sub-critical cracks grow under fatigue loading at relatively low strain levels below the COS until catastrophic failure, the details of which being essential for proper theoretical analysis. Similarly, the presence of stable cracks below the 
COS was related to the progressive resistance increases of $10 \%, 50 \%$ and $100 \%$ explicit in Table 2 .

\section{Conclusions}

The electro-fragmentation method originally developed to investigate the failure of conductive coatings on polymer substrates was extended to include dielectric coatings using an ultrathin conductive layer. Several dielectric coating/polymer substrate combinations representative of flexible electronic and packaging applications were investigated. A careful selection of the conductive probe layer was carried out to avoid artifacts resulting for instance from a change of the residual stress state of the investigated coating. The best results were obtained using ultrathin evaporated amorphous graphite layers. In contrast to Au and Al-Ti layers, and in the case of high temperature polymer substrates the graphite layer did not change the residual strain state in the dielectric coatings and its tensile failure was triggered by that of the dielectric coating. However, in the case of polymers (PET, PEN) with a glass transition temperature lower than the temperature reached during a-G evaporations a shift in crack onset strains was observed corresponding to a change of coating internal strain. This was argued to result from structural changes in the substrate induced by the thermal load during evaporation. The present method has been implemented to coating thicknesses down to $50 \mathrm{~nm}$, for films having strains to failure lower than that of the amorphous graphite layer. It provides a fast and accurate alternative to the time-consuming fragmentation test carried out in situ in a microscope. It allows automatic determination of the critical failure strain of dielectric coatings, and is a useful tool to investigate fracture mechanics theories.

\section{Acknowledgements}

The authors are grateful to the EU-funded Flexidis Project (IST 004354) for funding this work, and to the companies Unaxis Balzers Ltd., Displays Division, Philips and Tetra Pak Suisse S.A. for supplying samples. Victor Fernandez-Altable is acknowledged for support in XRD analysis.

\section{References}

[1] G.P. Crawford (Ed.), Flexible Flat Panel Displays, J. Wiley, Chichester, UK, 2005.

[2] O. Van der Sluis, R.A.B. Engelen, P.H.M. Timmermans, G.Q. Zhang, Proc. 9th Int. Conf. on Thermal, Mechanical and Multiphysics Simulation and Experiments in Micro-Electronics and Micro-Systems, EuroSimE 2008, Freiburg im Breisgau, Germany, 2008.

[3] H. Gleskova, I.C. Cheng, S. Wagner, J.C. Sturm, Z.G. Suo, Sol. Energy 80 (2006) 687.

[4] A.A. Abdallah, P.C.P. Bouten, J.M.J. Den Toonder, G. de With, Thin Solid Films 516 (2008) 1063.

[5] Y. Leterrier, L. Boogh, J. Andersons, J.-A.E. Månson, J. Polym. Sci., B, Polym. Phys. 35 (1997) 1449.
[6] G. Rochat, A. Delachaux, Y. Leterrier, J.-A.E. Månson, P. Fayet, Surf. Interface Anal. 35 (2003) 948.

[7] Y. Leterrier, L. Medico, F. Demarco, J.-A.E. Månson, U. Betz, M.F. Escola, M.K. Olsson, F. Atamny, Thin Solid Films 460 (2004) 156.

[8] D.R. Cairns, R.P. Witte, D.K. Sparacin, S.M. Sachsman, D.C. Paine, G.P. Crawford, R.R. Newton, Appl. Phys. Lett. 76 (2000) 1425.

[9] J. de Goede, P. Bouten, L. Médico, Y. Leterrier, J.-A.E. Månson, in Stability of Thin Films and Nanostructures, edited by R.P. Vinci, R. Schwaiger, A. Karim, and V. Shenoy (Mater. Res. Soc. Symp. Proc. vol. 854E, Warrendale, PA, 2005), U9.2.

[10] N.S. Lu, X. Wang, Z.G. Suo, J. Vlassak, Appl. Phys. Lett. 91 (2007).

[11] Z. Suo, J. Vlassak, S. Wagner, China Particuology 3 (2005) 321.

[12] A. Pinyol, B. Meylan, D. Gilliéron, V. Mewani, Y. Leterrier, J.-A.E. Månson, Proc. Large-Area Processing and Patterning for Active Optical and Electronic Devices, edited by V. Buloviæ, S. Coe-Sullivan, I. Kymissis, J. Rogers, M. Shtein, T. Someya (Mater. Res. Soc. Symp. Proc. vol. 1030E, Warrendale, PA, 2008), 1030-G03-12.

[13] M. Creatore, F. Palumbo, R. d'Agostino, P. Fayet, Surf. Coat. Technol. 142 (2001) 163.

[14] I. French, D. George, T. Kretz, F. Templier, H. Lifka, Soc. Info. Display Symp. Digest Techn. Papers, vol. 38, 2007, p. 1680 .

[15] J. Andersons, J. Modniks, Y. Leterrier, G. Tornare, P. Dumont, J.-A.E. Månson, Theor. Appl. Fract. Mech. 49 (2008) 151.

[16] G. Rochat, Y. Leterrier, P. Fayet, J.-A.E. Månson, Surf. Coat. Technol. 200 (2005) 2236

[17] H.S. Myung, Y.S. Park, B. Hong, J.G. Han, Y.H. Kim, J.Y. Lee, L.R. Shaginyan, Thin Solid Films 494 (2006) 123.

[18] G.A. Viana, R.G. Lacerda, F.L. Freire, F.C. Marques, J. Non-Cryst. Solids 354 (2008) 2135.

[19] D.R. Lide (Ed.), CRC Handbook of Chemistry and Physics, CRC Press, Boca Raton, FL, USA, 2000

[20] P. Dumont, G. Tornare, Y. Leterrier, J.-A.E. Månson, Thin Solid Films 515 (2007) 7437.

[21] P.H. Townsend, T.A. Brunner, J. Appl. Phys. 62 (1987) 4438.

[22] M. Ohring, Materials Science of Thin Films, Academic Press, San Diego, 2001.

[23] K. Röll, J. Appl. Phys. 47 (1976) 3224.

[24] Y. Leterrier, J. Andersons, Y. Pitton, J.-A.E. Månson, J. Polym. Sci., B, Polym. Phys. 35 (1997) 1463.

[25] G. Rochat, Y. Leterrier, P. Fayet, J.-A.E. Månson, Thin Solid Films 437 (2003) 204.

[26] M.T.A. Saif, S. Zhang, A. Haque, K.J. Hsia, Acta Mater. 50 (2002) 2779.

[27] D.H. Alsem, O.N. Pierron, E.A. Stach, C.L. Muhlstein, R.O. Ritchie, Adv. Eng. Mater. 9 (2007) 15.

[28] W.W. Van Arsdell, S.B. Brown, J. Microelectromechanical Syst. 8 (1999) 319.

[29] Y. Leterrier, C. Fischer, L. Médico, F. Demarco, J.-A.E. Månson, P.C.P. Bouten, J. de Goede, G. Nisato, J.A. Nairn, Proc. 46th SVC Ann. Tech. Conf., San-Francisco, 2003.

[30] Y. Ren, M. Baba, Y. Oishi, Jpn. J. Appl. Phys. Part 1. Regular Papers Brief Communications \& Review Papers 44 (2005) 1987.

[31] H. Stanjek, W. Hausler, Hyperfine Interact. 154 (2004) 107.

[32] S. Schelz, T. Richmond, P. Kania, P. Oelhafen, H.J. Guntherodt, Surf. Sci. 359 (1996) 227.

[33] H.A. Mizes, J.S. Foster, Science 244 (1989) 559.

[34] J.M. Ambrico, M.R. Begley, Thin Solid Films 419 (2002) 144.

[35] J.L. Beuth, Int. J. Solids Struct. 29 (1992) 1657.

[36] J. Dundurs, D.B. Bogy, J. Appl. Mech. 36 (1969) 650.

[37] J. Andersons, Y. Leterrier, G. Tornare, P. Dumont, J.-A.E. Månson, Mech. Mater. 39 (2007) 834.

[38] D.R. Cairns, G.P. Crawford, Proc. I.E.E.E. 93 (2005) 1451.

[39] W.A. MacDonald, M.K. Looney, D. MacKerron, R. Eveson, R. Adam, K. Hashimoto, K. Rakos, J. SID 15 (2007) 1075.

[40] B.A. Walmsley, A.J. Keating, Y. Liu, X.Z. Hu, M.B. Bush, J.M. Dell, L. Faraone, J. Appl. Phys. 102 (2007) 103517.

[41] T. Hanada, H. Furuya, S. Tanabe, N. Soga, J. Non-Cryst. Solids 152 (1993) 188.

[42] H.D. Espinosa, B.C. Prorok, J. Mater. Sci. 38 (2003) 4125.

[43] T.C. Hodge, S.A. Bidstrup-Allen, P.A. Kohl, IEEE Trans. Compon. Packag. Manuf. Technol. Part A 20 (1997) 241.

[44] L.A. Abel, J.R. Davis, Metals Handbook, ASM International, 1990.

[45] N. Alok, The Metals Databook, McGraw-Hill, New York, 1997. 